\title{
Method to integrate management tools aiming organizational excellence
}

\author{
Samuel Moretti Bernardo (D), lzabela Simon Rampasso ${ }^{\mathrm{b} *}$ (D), Osvaldo L.G. Quelhas ${ }^{\mathrm{c}}$ (D), \\ Walter Leal Filho ${ }^{\mathrm{d}}$ (i), Rosley Anholon ${ }^{\mathrm{a}}$ (i) \\ aUniversidade Estadual de Campinas, Faculdade de Engenharia Mecânica, Campinas, SP, Brasil \\ bUniversidad Católica del Norte, Departamento de Ingeniería Industrial, Antofagasta, Chile \\ 'Universidade Federal Fluminense, Programa de Mestrado em Sistemas de Gestão e Programa de Doutorado em Sistemas de \\ Gestão Sustentáveis, Niterói, RJ, Brasil \\ ${ }^{\mathrm{d}}$ Hamburg University of Applied Sciences, Faculty of Life Sciences, Hamburg, Germany \\ *izabela.rampasso@ucn.cl
}

\begin{abstract}
Paper aims: The main objective of this article is to present and validate a method to integrate multiple management tools aiming for organizational excellence in medium and large enterprises.

Originality: There is a scarcity of methods to integrate management tools to support companies in their operations. This study aims to fill this gap, proposing a manner for companies to perform this integration.

Research method: The method was developed considering tools and concepts well-established in the literature, such as Lean Thinking, Six Sigma, Balanced ScoreCard, among other management tools. The mentioned method was validated through a survey with managers and directors who are experts in organizational strategies. They were carefully selected considering their professional background.

Main findings: The proposed method provides an alignment between strategy and execution, presenting a cyclical characteristic to be continuously reviewed method, considering market needs. The survey verified the adherence of the method and to conclude that it is a feasible alternative to reach organizational excellence. Although integration of management methods is fundamental for companies to reach organizational excellence status, this kind of guidelines is scarce in the literature.
\end{abstract}

Implications for theory and practice: This method can be used to increase companies' performance and competitivity. Keywords

Strategy; Integration; Organizational Excellence.

How to cite this article: Bernardo, S. M., Rampasso, 1. S., Quelhas, O.L.G., Leal Filho, W., \& Anholon, R. (2022). Method to integrate management tools aiming organizational excellence. Production, 32, e20210101. https://doi.org/10.1590/01036513.20210101

Received: Aug. 20, 2021; Accepted: Dec. 1, 2021.

\section{Introduction}

In the information era, a substantial amount of data is provided for companies to support business management, to guide strategies and to obtain subsidies for the execution of the tactical plans, in order to increase its level of competitiveness. Knowledge is accessible to any company, which includes methods and management tools (Boulesnane \& Bouzidi, 2013; Dubey et al., 2019; Goecks et al., 2020; Hu et al., 2017; Meneghelli, 2016). The appropriate management of this knowledge is essential for companies' competitive advantage (Di Vaio et al., 2021). 
However, the primary question is still how to properly use this information to formulate and unfold strategies, in other words, how to transform them into subsidies that are capable of providing process optimization and the correct business direction, ensuring that the strategic goals can be achieved (Boulesnane \& Bouzidi, 2013; Ghalehkhondabi et al., 2020).

There is also another critical factor that still plagues companies. Associated with this volume of information that must be managed, there is a globalized, volatile and highly competitive market that exerts vast pressure on organizations, leaders and managers (Berman et al., 2010; Deif \& Elmaraghy, 2014; Nejatian et al., 2018). There is no room for mistakes, and inadequate targeting can lead to the decline of an entire company.

In this scenario, leadership abstention in the process is not always characterized as an element of neglect, but rather as the absence of a robust method that allows the unfolding of strategies within the complex environment in which they are inserted. The absence of a systemic view and an integrated process often leads leaders not to consider important elements for the success of an action (Kennerley \& Mason, 2008).

Mistaken decision-making or decision-making procrastination due to lack of subsidies can lead to failures in the implementation of strategies. A survey conducted in the mid-1980s with several management consultants showed that less than 10\% of the strategies formulated were successful (Kaplan \& Norton, 2000). The importance of organizational performance for strategic management is still evidenced in the literature (Ferreira et al., 2019; Hamann \& Schiemann, 2021).

It is also observed that in recent years companies have focused on the analysis of their external environment and formulation of their strategies, with little attention to issues related to their implementation (Cunha \& Borges, 2009; Stiles \& Taylor, 2002; Voola \& 0'Cass, 2010). In fact, the high mortality rate of business strategies is almost always related to problems of its implantation, not its formulation (Coulson $\square$ Thomas, 2013).

Regarding the available methodologies and management tools, an evolutionary process can be observed. Periodically, management tools are improved, new concepts are introduced, however, there is an internal misalignment in companies, where each manager uses a particular work method, which prevents the establishment of a unique language within companies (Nielsen et al., 2017).

The lack of integration not only has a negative influence on the strategic goals of the company, but it also gives it a greater level of inefficiency due to errors, rework, and duplication of team efforts, thus increasing operating costs. Despite the benefits of adopting an integrated management method, there is still no international standard or specific guidelines for its implementation (Llonch et al., 2018; Sampaio et al., 2012).

Specifically, in the case of tools for deploying strategies, there is a lack of methodologies, capable of ensuring that the outlined strategic goals reach all hierarchical levels and can be successfully set, especially in relation to the connection of strategies with the company routine and its linkages with other methodologies, in this sense, the gap in the literature is evidenced. Therefore, the research question that drives this research is: "How can the management tools be integrated to enable companies to achieve their strategic goals at every level?". For this, the following goals of this research were established: 1) to carry out a bibliographical review in order to identify methodologies and tools to allow the appropriate unfolding of the strategies and contribute to the proposition of an integration method; 2) to propose a method to integrate multiple management tools aiming organizational excellence in medium and large companies; 3) conduct a survey with professionals to find the answer to evaluate the degree of adherence and applicability of the method.

\section{Theoretical background}

The deployment and strategic execution process refer to the stage where planned strategies are actually developed by the organization, so that the desired goals can be achieved (Chatterjee et al., 2016). In essence, the strategy execution process must convert strategic goals into concrete results, which requires the adoption of efficient results-determination mechanisms for control and monitoring (Srivastava, 2013; Srivastava \& Sushil, 2015).

The most classic definitions related to strategy deployment refer to the promotion of organizational alignment, i.e. the dissemination of strategy to all organizational levels (Srivastava \& Sushil, 2017). lt is notorious that the very definition of the concept of strategy deployment implicitly suggests the need for an integration model that can enable this alignment. For Getz and Lee (2011), managing strategy execution requires well-orchestrated processes to lead strategies to the desired results.

Although the execution stage is neglected by most organizations and even business schools, that is a critical success factor for any type of strategy (Getz \& Lee, 2011; Voola \& 0'Cass, 2010). For some authors, the lack of execution ability by companies and their managers would be a major failure factor in brilliantly planned business, which has been almost an epidemic in today's corporate world (Raps, 2005; Speculand, 2009). In this 
same logical reasoning, some authors state that the greatest difference between a company and its competitors is exactly the ability to execute (Bossidy et al., 2002; Cocks, 2010; Floyd \& Wooldridge, 1990).

It is possible to present some examples of key tools associated with Strategic Formulation and Execution: SWOT matrix, Porter's 5 Forces, BCG Matrix, GE McKinsey Matrix, Business Model Canvas, Balanced ScoreCard (BSC), Hoshin Kanri, Four Disciplines of Execution Method (4DX) (Campbell, 2017; Henike et al., 2019; Mcchesney et al., 2013; Shen et al., 2015; Vuorinen et al., 2018). And, there are some complementary tools that can be integrated to the method: Competitive Analysis; Cash Flow; Sales Forecast; Sales and Operation Planning (S\&OP); Customer Sensitivity Analysis; Lean Six Sigma; Continuous Improvement Cycle (PDCA); Six Hats of Thought; Plan A3; Kaizen; Project Canvas; Project Management; Meritocracy Programs; Strategic Review Cycles (Blumentritt, 2006; Calandro Junior \& Lane, 2007; Cioffi, 2017; Huikku et al., 2017; lvert et al., 2015; Kim \& Choi, 2017; Muraliraj et al., 2018; Project Management Institute, Inc., 2017; Prybutok, 2018; Shamah, 2013; Tortorella et al., 2015).

Regarding to the management integrating models, Nunhes et al. (2017) argues that a truly integrated system combines management models focused on process vision, generating subsidies to all company practices and standards can be managed in a single system. According to Asif et al. (2011), in addition to the vertical integration required to ensure the dissemination of the strategy across all hierarchical levels and to promote a cycle of analysis and review of objectives, goals and processes, there must also be horizontal integration, to promote synergy between processes, departments and teams.

However, even with the wide discussion about the importance and the need to promote the integration of processes and management systems, there is practically no standard reference model for their implementation aiming the operational excellence. Operational excellence can be defined as a means to achieve process reliability through continuous improvement. It involves structuring control mechanisms that enable the company to regularly assess whether performance and targets are being met. In this way, processes can be evaluated and changed or modified when necessary or appropriate to produce better results (Zhang et al., 2016).

\section{Methodological procedures}

This section provides an overview of the research steps, as seen in Figure 1.

The first step of the process was to conduct a literature review, structured through research in renowned scientific bases. The objective was to clarify the concepts of strategic planning and execution, integration and operational excellence and also to carry out an extensive mapping of available methods and tools in the literature to support these concepts. Based on this information and on all identified gaps, the method of integrating multiple management tools was proposed in order to achieve organizational excellence in medium and large companies. The basic premise of this method was to enable the integration and synergy among the tools and methods considered. In especial, the method was developed to establish connections between planning and execution phases.

With the initial method designed, a survey script was structured containing validation questions. The script was structured in two parts, the first consisting of 15 multiple choice questions, presented in the form of statements to assess the participants' level of agreement with the proposed method, and 4 open-ended questions to point

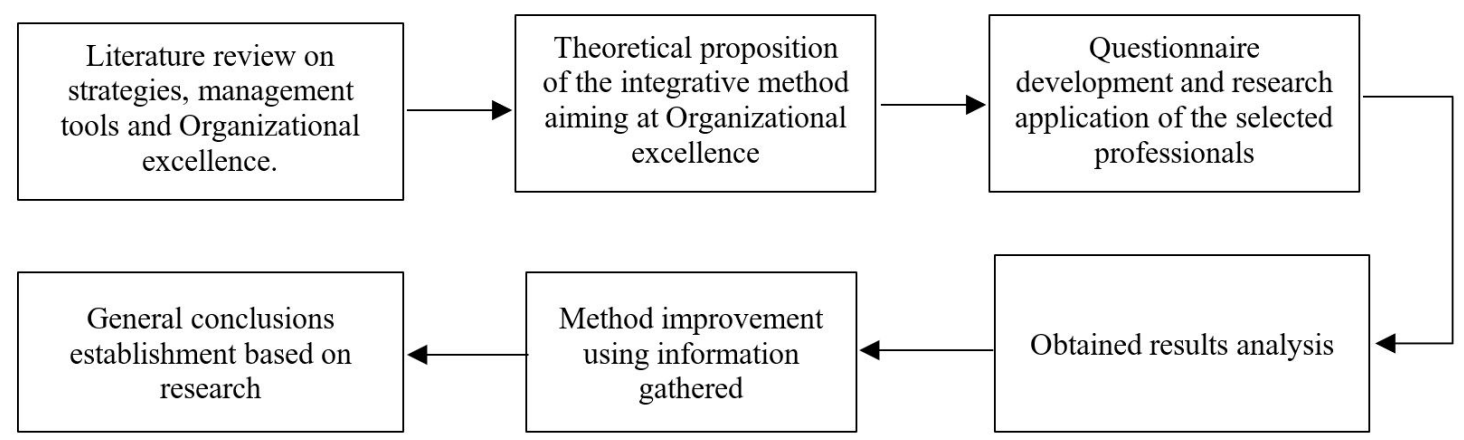

Figure 1. Research conducting steps. 
out the strengths and weaknesses of the method and show any adaptations. These questions are presented in Table 1.

The script was structured using the Google Form. An illustrative image and an explanatory video of the method were attached, being a pre-requisite for answering it. The creation of the video was necessary because it is not a trivial method and its full understanding requires a more detailed explanation. The script was approved by a Research Ethics Committee and the questionnaire was sent to 20 professionals holding strategic positions of medium and large companies from different segments. They were chosen through a non-probabilistic sampling, however the professional background were deeply analysed and it was selected only those presenting a relevant professional background, presenting experiences in several companies and being able to technicaly evaluate the difficulties and the method under analysis.

The data analysis was done considering convergence and trend for closed questions. This criterion considers that if 50\% of the answers or more are allocated to one of the criteria arranged in the defined likert scale, there is a convergence to that parameter. If no convergence is identified, it should be only assessed whether 50\% of the answers or more are displaced on the Likert scale above or below the neutral point, indicating a tendency for agreement or disagreement with the proposed method.

For the open questions, a critical analysis of the answers was performed using lramuteq software. With the consolidation of the research data, debates about the results obtained were held. In the final stage, the

Table 1. Questions presented in the survey.

\begin{tabular}{|c|c|c|c|c|c|}
\hline Question & & & Answer & & \\
\hline $\begin{array}{l}\text { Q1) Companies generally present serious } \\
\text { difficulties in implementing their strategies }\end{array}$ & $\begin{array}{l}\text { () Strongly } \\
\text { Disagree (SD) }\end{array}$ & () Disagree (D) & () Indifferent (1) & () Agree (A) & $\begin{array}{l}\text { () Strongly Agree } \\
\text { (SA) }\end{array}$ \\
\hline $\begin{array}{l}\text { Q2) There is a shortage of guidelines on how to } \\
\text { deploy strategies }\end{array}$ & $\begin{array}{l}\text { (0) Strongly } \\
\text { Disagree (SD) }\end{array}$ & () Disagree (D) & () Indifferent (1) & () Agree (A) & $\begin{array}{l}\text { () Strongly Agree } \\
\text { (SA) }\end{array}$ \\
\hline $\begin{array}{l}\text { Q3) There is a lack of guidelines regarding the } \\
\text { integration of management methods and tools }\end{array}$ & $\begin{array}{l}\text { () Strongly } \\
\text { Disagree (SD) }\end{array}$ & () Disagree (D) & () Indifferent (1) & () Agree (A) & $\begin{array}{l}\text { () Strongly Agree } \\
\text { (SA) }\end{array}$ \\
\hline $\begin{array}{l}\text { Q4) There is a lack of guidelines as to the path } \\
\text { that must be taken to achieve organizational } \\
\text { excellence }\end{array}$ & $\begin{array}{l}\text { () Strongly } \\
\text { Disagree (SD) }\end{array}$ & () Disagree (D) & () Indifferent (1) & () Agree (A) & $\begin{array}{l}\text { () Strongly Agree } \\
\text { (SA) }\end{array}$ \\
\hline $\begin{array}{l}\text { Q5) The presented method shows guidelines for } \\
\text { strategy deployment }\end{array}$ & $\begin{array}{l}\text { () Strongly } \\
\text { Disagree (SD) }\end{array}$ & () Disagree (D) & () Indifferent (1) & () Agree (A) & $\begin{array}{l}\text { () Strongly Agree } \\
\text { (SA) }\end{array}$ \\
\hline $\begin{array}{l}\text { Q6) The presented method shows guidelines for } \\
\text { the integration of management methods and } \\
\text { tools }\end{array}$ & $\begin{array}{l}\text { () Strongly } \\
\text { Disagree (SD) }\end{array}$ & () Disagree (D) & () Indifferent (1) & () Agree (A) & $\begin{array}{l}\text { () Strongly Agree } \\
\text { (SA) }\end{array}$ \\
\hline $\begin{array}{l}\text { Q7) The method presented can be fully } \\
\text { implemented in your company }\end{array}$ & $\begin{array}{l}\text { () Strongly } \\
\text { Disagree (SD) }\end{array}$ & () Disagree (D) & () Indifferent (1) & () Agree (A) & $\begin{array}{l}\text { () Strongly Agree } \\
\text { (SA) }\end{array}$ \\
\hline $\begin{array}{l}\text { Q8) The tools presented are in line with the } \\
\text { reality of your company }\end{array}$ & $\begin{array}{l}\text { () Strongly } \\
\text { Disagree (SD) }\end{array}$ & () Disagree (D) & () Indifferent (1) & () Agree (A) & $\begin{array}{l}\text { () Strongly Agree } \\
\text { (SA) }\end{array}$ \\
\hline $\begin{array}{l}\text { Q9) The presented method can be implemented } \\
\text { in companies of the same segment in which your } \\
\text { company operates }\end{array}$ & $\begin{array}{l}\text { (0) Strongly } \\
\text { Disagree (SD) }\end{array}$ & () Disagree (D) & () Indifferent (1) & () Agree (A) & $\begin{array}{l}\text { () Strongly Agree } \\
\text { (SA) }\end{array}$ \\
\hline $\begin{array}{l}\text { Q10) The proposed method can contribute to } \\
\text { improving the performance of your organization }\end{array}$ & $\begin{array}{l}\text { () Strongly } \\
\text { Disagree (SD) }\end{array}$ & () Disagree (D) & () Indifferent (1) & () Agree (A) & $\begin{array}{l}\text { () Strongly Agree } \\
\text { (SA) }\end{array}$ \\
\hline $\begin{array}{l}\text { Q11) The proposed method is able to bridge the } \\
\text { gap between planning and strategy execution }\end{array}$ & $\begin{array}{l}\text { () Strongly } \\
\text { Disagree (SD) }\end{array}$ & () Disagree (D) & () Indifferent (1) & () Agree (A) & $\begin{array}{l}\text { () Strongly Agree } \\
\text { (SA) }\end{array}$ \\
\hline $\begin{array}{l}\text { Q12) The proposed method can be incorporated } \\
\text { by the leadership of your company }\end{array}$ & $\begin{array}{l}\text { () Strongly } \\
\text { Disagree (SD) }\end{array}$ & () Disagree (D) & () Indifferent (1) & () Agree (A) & $\begin{array}{l}\text { () Strongly Agree } \\
\text { (SA) }\end{array}$ \\
\hline $\begin{array}{l}\text { Q13) Potential returns from the implementation } \\
\text { of the proposed method justify your investment } \\
\text { (human and financial capital) }\end{array}$ & $\begin{array}{l}\text { () Strongly } \\
\text { Disagree (SD) }\end{array}$ & () Disagree (D) & () Indifferent (1) & () Agree (A) & $\begin{array}{l}\text { () Strongly Agree } \\
\text { (SA) }\end{array}$ \\
\hline $\begin{array}{l}\text { Q14) The level of integration between the tools } \\
\text { presented in the method was satisfactory }\end{array}$ & $\begin{array}{l}\text { (0) Strongly } \\
\text { Disagree (SD) }\end{array}$ & () Disagree (D) & () Indifferent (1) & () Agree (A) & $\begin{array}{l}\text { () Strongly Agree } \\
\text { (SA) }\end{array}$ \\
\hline $\begin{array}{l}\text { Q15) The complexity level of the method is } \\
\text { adequate given the complexity of its purpose } \\
\text { (providing synergy between processes and } \\
\text { directing the organization to organizational }\end{array}$ & $\begin{array}{l}\text { () Strongly } \\
\text { Disagree (SD) }\end{array}$ & () Disagree (D) & () Indifferent (1) & () Agree (A) & $\begin{array}{l}\text { () Strongly Agree } \\
\text { (SA) }\end{array}$ \\
\hline
\end{tabular}
excellence).

Open-ended questions

Q1) What are the strengths observed in the method?

Q2) What are the weaknesses observed in the method?

Q3) Which improvements would you point out about the method?

Q4) Would you add and/or remove any methodological tools? 
conclusions regarding the research objectives were established considering the obtained results, so the initial hypothesis formulated regarding the viability of the proposed method could be validated.

\section{Results and discussions}

\subsection{Theoretical presentation of the proposed method}

The proposed method is structured to provide alignment between strategy and execution. It has a cyclical characteristic, i.e. it is not a static methodology, but a continuous review method, connected with the philosophy of the continuous improvement cycle and adhering to current market needs. Figure 2 presents the proposed method.

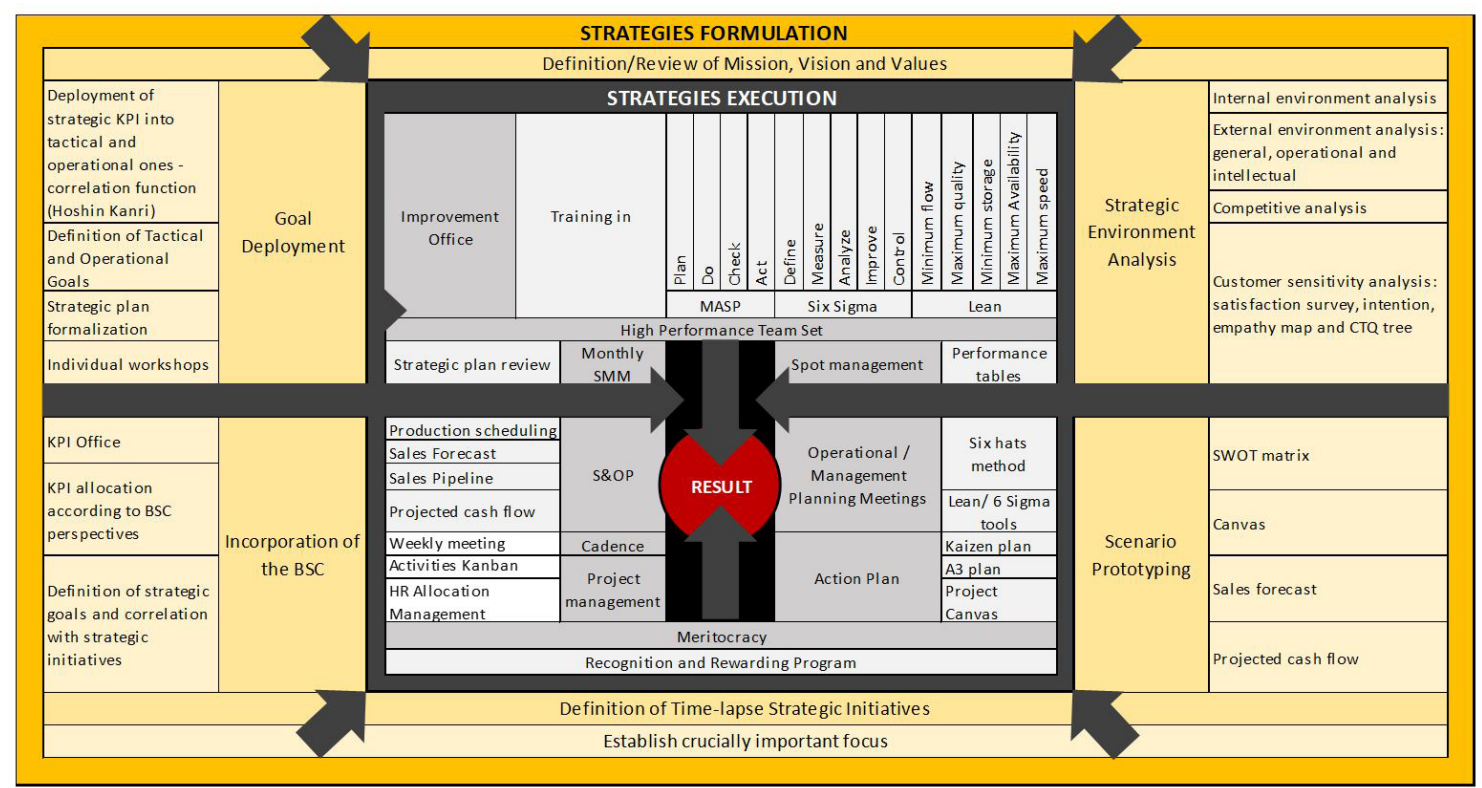

Figure 2. Proposed integration method.

The steps of method implementation will be presented in sequence, starting with the strategy formulation layer.

a) Definition/Review of Mission, Vision and Values: The first step of the process is the elaboration or review of its mission and organizational vision, if there are any. This stage should always be analyzed in the first instance because it reflects the yearnings of the organization and consequently of the individuals who lead it. This does not mean that the mission and vision cannot be revisited during the strategic planning development process. Quite to the contrary, this is a natural process and should in fact take place because it is also the role of strategic planning not only to signal the paths to achieve a result, but also to present the limitations or impediments that may make a future vision unfeasible.

b) Strategic Environment Analysis: The next step refers to the analysis of the internal and external environment to which the company operates. In the analysis of the internal environment, an in-depth assessment of the organizational structure should be conducted, identifying the potentialities capable of sustaining the capitalization of business opportunities and the internal weaknesses of the organization, which must be addressed so that the company does not face threats of competition. The internal environment analysis considers the evaluation of six different aspects, as recommended by Biagio and Batocchio (2005): Organisational, marketing, personal / HR, production / operation, financial and technological aspects. This analysis can be done through process mapping or using structured checklists, as available in the Canvas Model (Osterwalder \& Pigneur, 2010). All points raised should be prioritized according to their level of relevance. Similarly, in analyzing the external environment, we 
must assess the opportunities and threats that permeate the market in which the company operates. In the analysis, we must consider all market components, such as economic, social, political and technological. For this mapping we can also use structured checklists, available in the literature. It is recommended that the external environment review process be conducted in a workshop attended by managers, directors, supervisors and other relevant resources. The more heterogeneous the group, the richer the analyzes will be. The points raised in this step should also be prioritized according to their level of relevance. This stage should also conduct a detailed mapping of the organization's direct competitors. Next, the main characteristics of these competitors as well as their strengths and weaknesses should be identified. You should evaluate the bets or investment targeting of these competitors for future projects. This analysis is crucial especially for the complementary identification of potential threats. Another key action to be taken at this stage is customer sensitivity analysis, so that it is possible to identify the value-adding elements. This analysis is critical for a company to tailor its products and services to meet the expectations of its target audience. In order to make this evaluation, it is necessary to carry out research in specialized magazines and websites, to apply satisfaction and intent surveys, and to structure a map of empathy through group dynamics. This tool aims to map the customers profile as well as their preferences.

c) Scenario Prototyping: Stage of the method where the strategy formulation process should begin by prototyping the scenarios envisioned for the business and taking sales and cash projections as a reference. Initially, a SWOT matrix should be structured to correlate market opportunities and threats with identified strengths and weaknesses. Based on the outputs of the SWOT matrix, the scenario prototyping process provided by the Canvas frame should be started. Thus, the following elements must be specified: customer segment; value offer; channels; relationship with customers; sources of revenue; key resources; key activities, strategic partnerships and cost structure. Through this method, it is possible to build different scenarios, testing different strategies and market positions. Structured business scenarios should consider sales forecasts for future periods. Forecasts, in turn, must be supported by statistical forecasting models. With the forecasts available, cash flow projections should also be made, which will also influence structured business models. Thus, it will be possible to simulate if the organizational results are acceptable, which means, if the business is able to pay all fixed and variable costs and still generate the profitability necessary to enable its operationalization against the risks inherent to the business and the cost of capital. It will be based on this analysis that the company should structure its budget, i.e. the strategy and the budget must be in full synergy.

d) Definition of Time-lapse Strategic Initiatives: At this stage of the method, strategic initiatives should be conducted according to the validated scenario prototype should be established. The purpose is to convert the desired strategic objectives into initiatives that can be fully interpreted by the teams responsible for the execution. There is usually a much larger volume of initiatives than the organization has the capacity to execute. For this reason, and taking the four disciplines of implementation method as a reference (Mcchesney et al., 2013), initiatives should be assessed considering the focus on the crucially important, i.e. considering that for the start of the strategy implementation process, some initiatives outweigh others in the importance requirement and therefore need to be prioritized. In this step we can use a prioritization matrix.

e) Incorporation of the BSC: With the prioritized initiatives, the BSC should then be incorporated, establishing correlations with the indicators that will be used to measure its effectiveness. The process begins by surveying all available indicators in the organization through a KPl workshop. In this dynamic the gaps are also identified that indicate the need to create new indicators. The set of mapped indicators should be distributed according to BSC perspectives, establishing the cause and effect links between the financial and non-financial indicators, and the selected strategic initiatives. At the end, the targets for each indicator associated with a strategic initiative should be specified. These goals must also be tracked over time to achieve the desired levels of excellence for the business.

f) Goal Deployment: The last step to be defined for the strategic layer, prerequisite for the officialization of the plan for all organizational levels, representing the transition to the execution phase. This stage begins with the deployment of strategic indicators into tactical and operational processes. It is also important to pay attention to the characteristic of these indicators. According to Mcchesney et al. (2013) they must have driving characteristics rather than results, that is, they must be predictable and influential. The work team needs to be able to see that their actions are influencing the outcome of an indicator for which they have responsibility. It is an engagement mechanism. The tying of these multi-level indicators with the strategic initiatives to be conducted by their respective managers can be established through an X matrix employed in the Hoshin Kanri methodology. An important consideration is that at this time an analysis should be carried out to verify if there are strategic initiatives to make it possible to achieve all the goals, or if the initiatives raised will be enough to guarantee the desired results. This way small adjustments can be applied at this stage. 
Finally, the goals of the tactical and operational level indicators should be set by reference to the expected results for the strategic level indicators. Once the strategic plan has been consolidated, it should be made official to the entire organization, with the presence of the president, directors and managers. An intensive campaign should also be undertaken to publicize the roles and responsibilities of each area, department and individual within the strategic execution process. Immediately after the official announcement, each manager should conduct an individual workshop with their respective teams to explain the objectives, initiatives and goals to be achieved. In addition, the process of execution, monitoring and periodic review of the strategies, elements of the second layer of the proposed method, should be explicit. It is recommended that all leaders must be trained in advance so that they can conduct the workshop considering the same standards and language of communication. Once this step is completed, the method implementation layer begins where there are three main pillars that support the cycle objectives and goals review, the improvement office pillar, the high performance team building pillar and the of meritocracy. In the following, these three pillars will be detailed.

g) Improvement Office: internal entity that should be established with the objective of boosting the strategic initiatives of the organization and promoting the continuous improvement process. It is a powerful mechanism to ensure that all improvement actions can be developed internally through structured working methods such as the Problem Analysis and Solution Method (PASM) and the use of project management techniques. In this way, the improvement office must ensure that the outlined strategies are implemented in the day by day of organizations, either through Kaizen events, building improvement action plans, or developing more complex projects. For this reason, the improvement office is said to be the facilitator of improvement strategies and actions. In addition, its goal is to ensure that all departments of the company are perfectly aligned and focused on the performance indicators of interest to the organization.

h) High Performance Team Set: One of the key points of the proposed method refers to the special attention given to the development of human resources to create high performance teams. This ideology is related to the fact that human and intellectual capital are the greatest agents of execution, transformation and innovation. Human resource development directly implies organizational development.

The recommended human resources training program should consider the particular intellectual level of each organization / department and should follow an evolution plan over time (knowledge track). Regardless of what stage the organization is in, the training plan should consider continuous improvement cycles and other lean tools.

i) Meritocracy - Recognition and Reward Program (RRP): Another key point of the method concerns the idea of meritocracy. The structuring of a RRP links the achievement of goals to the recognition and reward of human resources, thus stimulating people's motivation and creating an environment prone to the generation of new ideas and innovation. Variable compensation programs must be connected with corporate strategies and the objectives pursued by the company. This initiative ensures that the focus is directed to the indicators of interest of the organization.

Once the implementation tripod is structured, the strategy implementation cycle effectively begins.

j) Spot Management - Performance Tables: Throughout the strategic execution process, it should be ensured that all areas have a scoreboard with the main performance indicators that should be monitored daily. Responsibility for updating and exposing performance indicators should lie with area leaders. However, it is the Improvement Office's responsibility to monitor and charge leaders if these indicators are out of date. The use of sight management encourages teams to engage in achieving results.

k) Management Planning Meeting (MPM) and Operational Planning Meeting (OPM): These represent meetings to discuss how strategies will be implemented, how problems will be resolved, and how new opportunities will be addressed. Whenever an indicator exposed at the strategic management meeting is off target and the strategic committee is asked to direct corrective, preventive, or containment action, it will trigger the need for an MPM or OPM. For the most complex problems or actions that represent the need to develop a project, an MPM should be convened with the presence of managers and leaders. For actions that are not characterized as a project, an OPM should be scheduled with the presence of leaders and other key collaborators in the area.

Meetings must follow the Six Hats dynamics of thought so that they can be efficient and effective. At this meeting all improvement techniques and tools should be employed extensively. The main purpose of the meeting is to get the draft of a new action plan or even guidelines for reviewing an ongoing action plan. 
I) Structuring the Action Plans: At the end of the meetings, the leader of the action should structure the detailed implementation plan with the support of the improvement office, which will assist in the project management aspects (discussed below), establishing the actions, the leaders and the deadlines for the completion of each action outlined.

Strategy improvement or deployment plans can be formatted into three different document types: Kaizen / $5 \mathrm{~W} 2 \mathrm{H}$ form for initiatives that represent low or non-existent investment and can be completed within 1 month; A3 map form for medium investment initiatives that can be completed within 3 months; and Project Canvas form for initiatives that require high investment and are usually completed within 3 months.

m) Project Management: The improvement office is also responsible for managing the timelines of all action plans and the allocation of all resources involved. To do this, after approval of an action plan, you must enter all planned activities into a kanban action management model. The kanban model of action management is nothing more than a way of organizing activities. In terms of resource allocation monitoring, the improvement office also plays a key role in constantly assessing whether any resources are overloaded. This concern is in line with Mcchesney et al. (2013) approach that resources lose focus and quality of execution when they undergo an exacerbated number of improvement activities added to their daily work routine.

n) Weekly Cadence Meetings: After structuring the action plans, the improvement office should, along with the person designated for the results of the action plan, initiate the weekly follow-up of the planned actions. These are the cadence meetings that according to Mcchesney et al. (2013), represents the most important method discipline of the four disciplines of execution.

Cadence meetings should last no more than 30 minutes, and should involve all employees with actions provided for in the plan, and should also always follow the same agenda: accountability (reporting commitments), signaling difficulties, reviewing status and planning. actions to be developed by the next cadence meeting. It is important to state that in this method, employees assume responsibility for delivering the plan to their team members and no longer through the imposition of leaders or managers.

o) Sales and Operations Planning (S\&OP): The proposed method also considers the integration of the S\&OP cycle, using its information and projections as a mechanism of confrontation between the planned scenario (strategic plan) and the projected scenario (S\&OP). S\&OP conciliation meetings are crucial as they direct all strategies in areas such as production scheduling and consequently purchasing, as well as directing the sales effort. Thus, the connection of the S\&OP to the strategic map is the trigger for eventual course adjustment. For this reason, the outputs of the S\&OP should be the inputs of the SMMs.

p) Review of the Strategic Plan - Strategic Management Meetings (SMMs): represents one of the key elements of the proposed method. SMMs should occur monthly at the beginning of the month when the S\&OP cycle is complete and all indicators from the previous month are consolidated for evaluation. SMMs should preferably take place on the same day and represent meetings of managers, directors and the president of the organization to evaluate performance indicators related to corporate strategies of the company. Accordingly, each manager or director responsible for the strategic level indicator should be accountable for the indicator's performance versus the target set. If the strategic indicator has not achieved the desired goal, a more detailed analysis should be carried out, assessing which of the tactical and operational level indicators linked to it have not reached the target either.

Following analysis, actions should be suggested so that off-target indicators can achieve their optimal performance in the next evaluation cycle. These suggestions will be dealt with later in OPMs and MPMs supported by the enhancement office.

\subsection{Results from proposed method assessment survey}

The consolidation of the research allowed the identification of very satisfactory results regarding the participants' level of agreement about the proposed method. Figure 3 presents the synthesis of these results.

In the open questions evaluation, more specifically in question one, it was found a high agreement that the method serves its purpose by establishing the integration of multiple management tools and acting at the critical point of the process, which is at the interface between the planning and strategic execution. The similarity map generated by the lramuteq software shows the connection between the mentioned points, as shown in Figure 4 . 


\begin{tabular}{|c|c|c|c|c|c|c|c|}
\hline Questions & SD & D & I & $\mathbf{A}$ & SA & Results & Analysis \\
\hline 1 & $0 \%$ & $5 \%$ & $10 \%$ & $30 \%$ & $55 \%$ & Convergence & $\begin{array}{l}55 \% \text { of respondents fully agree that companies generally have serious } \\
\text { difficulties in applying their strategies }\end{array}$ \\
\hline 2 & $0 \%$ & $15 \%$ & $15 \%$ & $45 \%$ & $25 \%$ & Trend & $\begin{array}{l}45 \% \text { of participants agree and } 25 \% \text { totally agree that there is alack of } \\
\text { guidelines on how to deploy strategies, i.e. } 70 \% \text { of the sample tends to } \\
\text { agree }\end{array}$ \\
\hline 3 & $0 \%$ & $10 \%$ & $10 \%$ & $30 \%$ & $50 \%$ & Convergence & $\begin{array}{l}50 \% \text { of participants fully agree that there is a lack of gui delines regarding } \\
\text { the integration of management methods and tools }\end{array}$ \\
\hline 4 & $0 \%$ & $15 \%$ & $5 \%$ & $50 \%$ & $30 \%$ & Convergence & $\begin{array}{l}50 \% \text { of respondents agree that there is a lack of guidelines as to the path } \\
\text { that should be taken to achieve organizational excellence }\end{array}$ \\
\hline 5 & $0 \%$ & $0 \%$ & $0 \%$ & $75 \%$ & $25 \%$ & Convergence & $\begin{array}{l}70 \% \text { of participants agree that the method indicates guidelines for strategy } \\
\text { depl oyment }\end{array}$ \\
\hline 6 & $0 \%$ & $0 \%$ & $0 \%$ & $75 \%$ & $25 \%$ & Convergence & $\begin{array}{l}75 \% \text { of participants agree that the method presented signals guidelines for } \\
\text { the integration of management methods and tools }\end{array}$ \\
\hline 7 & $0 \%$ & $0 \%$ & $10 \%$ & $70 \%$ & $20 \%$ & Convergence & $\begin{array}{l}70 \% \text { of participants agree that the method presented can be fully } \\
\text { implemented in their respective companies }\end{array}$ \\
\hline 8 & $0 \%$ & $0 \%$ & $15 \%$ & $70 \%$ & $15 \%$ & Convergence & $\begin{array}{l}70 \% \text { of participants agree that the tools presented are connected to the } \\
\text { reality of their companies }\end{array}$ \\
\hline 9 & $0 \%$ & $0 \%$ & $0 \%$ & $75 \%$ & $25 \%$ & Convergence & $\begin{array}{l}75 \% \text { of participants agree that the method presented can be implemented in } \\
\text { companies of the same operational segment }\end{array}$ \\
\hline 10 & $0 \%$ & $0 \%$ & $0 \%$ & $60 \%$ & $40 \%$ & Convergence & $\begin{array}{l}60 \% \text { of participants agree that the proposed method can contribute to } \\
\text { improve the performance of their companies }\end{array}$ \\
\hline 11 & $0 \%$ & $5 \%$ & $15 \%$ & $70 \%$ & $10 \%$ & Convergence & $\begin{array}{l}70 \% \text { of participants agree that the proposed method is able to bridge the } \\
\text { gap between planning and execution of strategies }\end{array}$ \\
\hline 12 & $0 \%$ & $0 \%$ & $15 \%$ & $70 \%$ & $15 \%$ & Convergence & $\begin{array}{l}70 \% \text { of respondents agree that the proposed method can be incorpor ated by } \\
\text { the leadership of their companies }\end{array}$ \\
\hline 13 & $0 \%$ & $0 \%$ & $15 \%$ & $60 \%$ & $25 \%$ & Convergence & $\begin{array}{l}60 \% \text { of participants agree that potential returns from implementing the } \\
\text { proposed method justify their investment (human and financial capital) }\end{array}$ \\
\hline 14 & $0 \%$ & $0 \%$ & $15 \%$ & $65 \%$ & $20 \%$ & Convergence & $\begin{array}{l}65 \% \text { of participants agree that the level of integration between the tools } \\
\text { presented in the method was satisfactory }\end{array}$ \\
\hline 15 & $0 \%$ & $5 \%$ & $25 \%$ & $55 \%$ & $15 \%$ & Convergence & $\begin{array}{l}55 \% \text { of participants agree that the method complexity level is appropriate } \\
\text { given the complexity of its purpose (providing synergy between processes } \\
\text { and directing the company to organizational excellence) }\end{array}$ \\
\hline
\end{tabular}

Figure 3. Summary of search results.

Regarding question 2, in which participants were asked about the weaknesses of the method, the main notes were: $32 \%$ mentioned the complexity level of the method; $26 \%$ said they did not identify a weakness; $11 \%$ mentioned the absence of aspects related to organizational culture change or management change; and $11 \%$ mentioned the difficulty of execution, which can, in a broader analysis, also be linked to the complexity of the method and the need to promote management change.

In question 3, in which participants were asked to indicate improvements to the proposed method, the most mentioned terms were identified: inclusion of management change, method synthesis to reduce the complexity level, and application of technology to support deployment.

Regarding question 4, in which participants were asked to indicate the need to include or exclude any tool in the method, a huge majority indicated no need. 


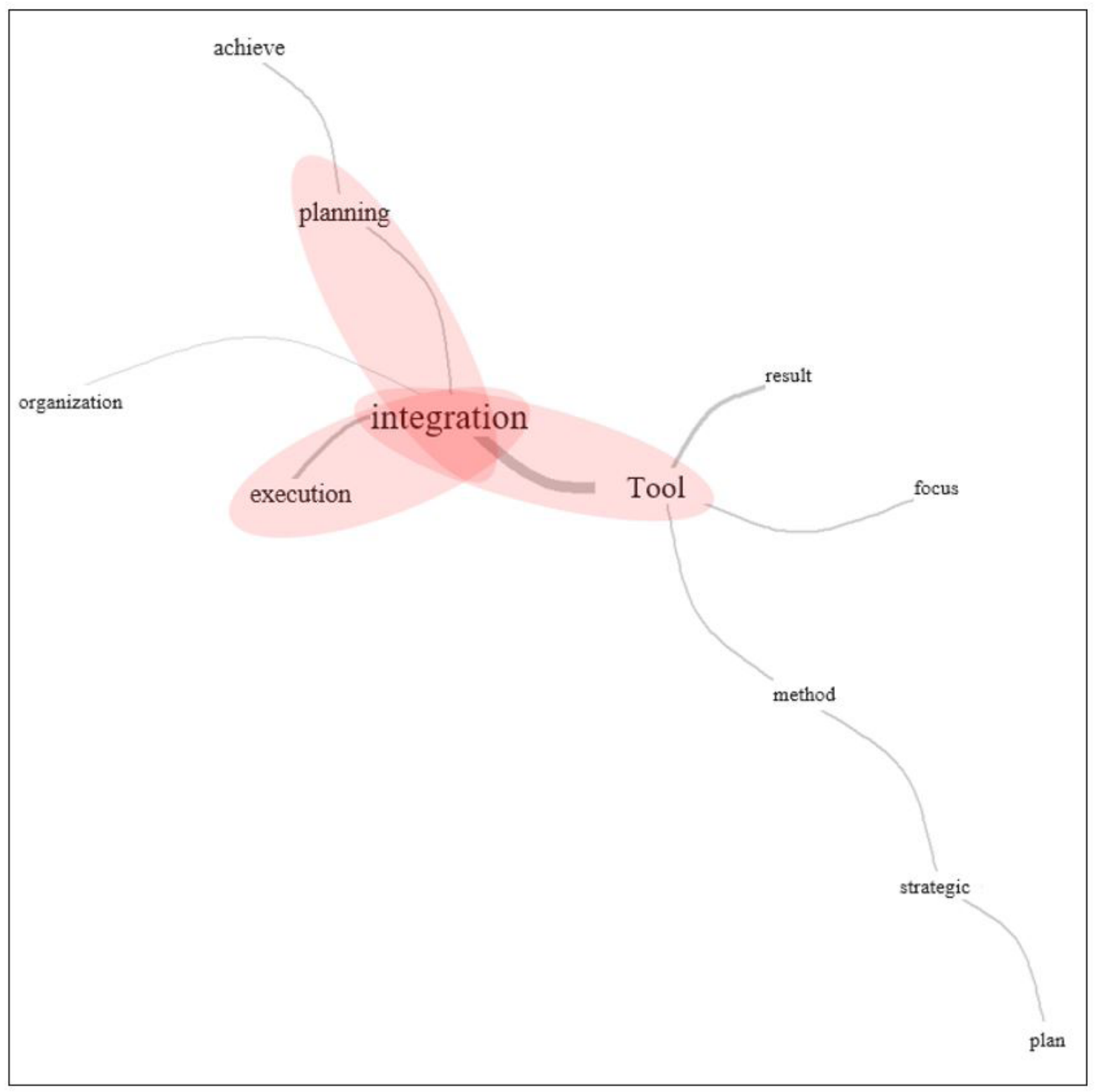

Figure 4. Similarity analysis for the strengths identified in the method.

\subsection{Discussion}

Lately, the high mortality rate of strategies developed by organizations has been very much addressed in the literature. In this survey, again this was a clear issue, where about $85 \%$ of respondents indicated that they agree $(30 \%)$ or totally agree $(55 \%)$ that companies generally have serious difficulties in implementing their strategies. This question was firstly addressed because it aimed, in the first instance, to validate whether this aspect was also perceived by the participants as critical for their organizations, since the proposed integration method has as one of its main objectives to improve the performance of organizations in this regard.

Another issue validated by the research refers to the lack of guidelines on how to deploy strategies, where $70 \%$ of participants indicated that they agree $(45 \%)$ or totally agree $(25 \%)$ that this is a current problem faced by organizations. Once again the gap between planning and execution is evident. Moreover, it was found that this is not an exclusive problem of small companies, since the target audience of this research concentrated in medium and large companies.

Similarly, participants were asked about the scarcity of guidelines regarding the integration of management methods and tools, and again the result showed the criticality of the issue, where $80 \%$ of participants indicated 
that they agree $(30 \%)$ or totally agree (50\%) with this statement. This result is also in line with the bibliographic survey and once again reinforces the problem related to the lack of a guideline to promote the integration of management systems.

Linked to these factors, showing the lack of guidelines as to the path that must be taken to achieve organizational excellence, reinforces the importance of the proposed method.

The analyzes subsequently focused on answering the main research question: once the method was conceived, what would be its degree of adherence and applicability to the reality of medium and large organizations?

As evidenced by the results presented, the positioning of the research participants in relation to the proposed method was very favorable, indicating their adherence to the reality of companies and, therefore, qualifying it as a possible and viable way to pursue organizational excellence. This condition can also be reinforced by signaling the various positive factors listed by participants in the first open question.

Regarding the negative points and improvements to be applied in the method, all the notes observed were in the character of recommendations. The aspect most cited by the respondents refers to the degree of complexity of the method. However, it is important to clarify that the integration process is not a trivial activity and demands a more robust and structured solution. Another important fact is that the integration method implementation process does not occur all at once. This is a gradual and phased deployment process, so it is not expected to be implemented at one time. This gradual process is also healthy because the method seeks to promote cultural change in the organization, and this type of change does not occur at an accelerated rate.

Another topic mentioned by the respondents in this analysis strand refers to the lack of a management process change for the implementation method. On this issue, it is important to state that such a program needs above all of top management. This is the first step to be taken to enable the method. Once senior management is willing to support its implementation, creating the necessary conditions for teams to exercise it properly, the method itself in its structure already contemplates the change process. The change of mindset and consequently of the organizational culture are more strongly associated with the formation pillars of high performance teams, in which the training process tends to develop people's vision and behavior; the recognition and reward program, which encourages meritocracy and results-based management; and the cadence meetings and the active performance of the improvement office, which is responsible for speeding up the actions necessary to achieve the goals.

Regarding the suggestion about the use of technology to support the method implementation, although it has not been explained, it is understood that there is full adherence. Increasingly, companies are technologydependent and the organization's level of technology maturity may be a facilitator for implementation. Another strand of analysis concerns the full systematization of the method, which could represent an even greater level of integration for organizations. This systematization is a market trend and is connected with the so evident precepts of industry 4.0. However, it is understood that this evolution requires a maturation of the postimplantation method.

\subsection{Integration method improvements}

Given the lack of a denser adequacy point observed by the research participants, the improvements presented were intended to act on the perception of respondents about the method complexity level. Thus, it acted in two main aspects, in the flexibility regarding the adoption of some tools, without interference in the method implementation cycle, and in the phasing of its steps.

In the first aspect, the flexible tools were: (1) Canvas frame, which does not prevent the operation of the method, but facilitates the business vision; (2) Hoshin Kanri that facilitates the connection of goals with strategic initiatives, however, can be absorbed by BSC if applied correctly; (3) training, can and should start from the basics depending on the maturity level of the organization; (4) the six hat technique is a facilitator but not overweight; (5) use of three modalities of action plans can be reduced or standardized to a single model; (6) Activity kanban is one of the ways to manage running projects, but there may be others; (7) S\&OP may be incorporated later provided that the company has demand forecasting techniques and cash flow projections.

In the second part, the method was divided into four implantation phases, as evidenced by Figure 5 .

The first phase covers the entire strategy formulation layer and has an estimated six-month implementation deadline. Phase two covers the main elements of execution and includes basic process improvement training, monthly strategic plan follow-up meetings (SMMs), the adoption of sight management practices, the implementation of MPMs and OPMs, the structuring of plans. the implementation of the cadence meeting culture and the structuring of the meritocracy program. For this phase an implementation period of 12 months is estimated. 


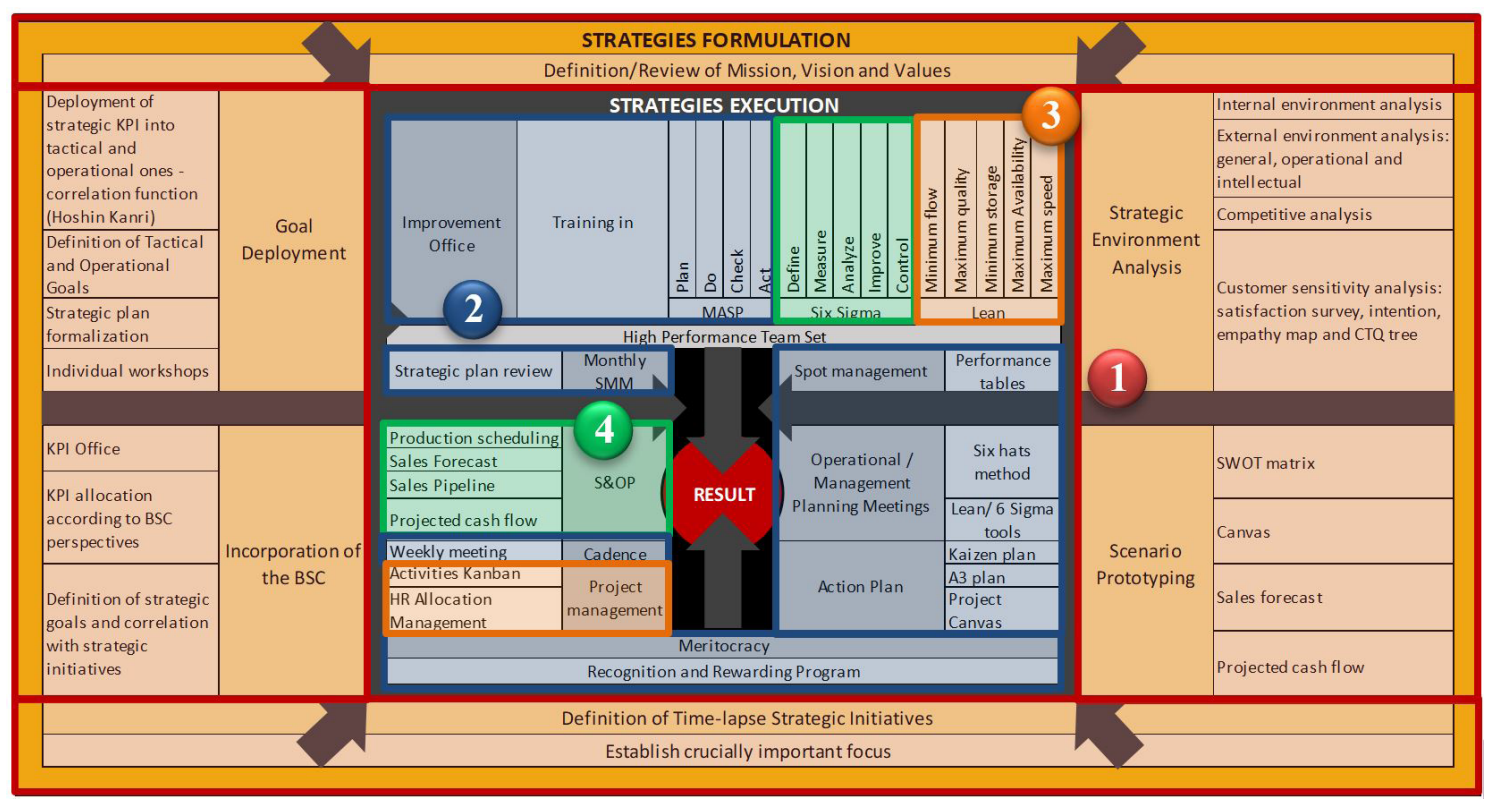

Figure 5. Method implementation phases.

Phase three considers the evolution of training to apply more refined Lean techniques and the adoption of project management practices. Finally, phase four includes yet another evolution of training considering six sigma practices that will help teams lead improvement projects and incorporate the S\&OP cycle to increase the company's predictability and make information even more integrated.

\section{Conclusion}

Faced with the complex scenario in which companies are inserted, there is an increasing challenge of keeping competitive. Challenges abound, such as the difficulty of assertive decision-making by the leadership in the face of an huge volume of information to be managed simultaneously, volatile and uncertain market, a gap between planning and execution, the absence of guidelines regarding leadership participation in the strategy deployment process and especially the difficulty of systemically managing through the integration of management methods, which are fundamental for companies to achieve the state of organizational excellence. However, as evidenced by the research conducted, a method or guideline directed to this end is practically non-existent in the literature. Given this scenario, the main goal of this research was to propose a viable alternative, through a structured method, so that companies can seek the level of integration and excellence, thus raising the management and results levels and consequently providing business competitiveness for the company.

After proposing the method using all theoretical framework researched, a survey with 20 professionals was applied to assess the level of agreement and its level of adherence. Overall, the results were very satisfactory and showed that the proposed integration method effectively fulfills its objective, constituting a very viable alternative for organizations to actually eliminate the gap between planning and strategic execution, promote the integration and leverage results toward the state of organizational excellence.

It is also important to point out that, besides the practical relevance of the method, there is also the academic relevance, as mentioned, there is a great lack of relevant academic materials with this theme and new studies may be directed towards proposing new approaches to this method or even to alternative methods, based on this research. We also highlight that the systemic integration of the management tools validated can be useful for researchers in their future studies. Among the future research possibilities, we highlight the conduction of an action research implementing the proposed model in a company and evaluating the effects of it.

Finally, it is important to note that this is still a theoretical method and needs to be implemented so that all assessed benefits can be confirmed. In addition, as any management system, the method should be analysed by the companies in order to adequate its features to their realities. However it is clear that the benefits are numerous and there is a huge potential for success given the perceptions raised in this research. 


\section{References}

Asif, M., Searcy, C., Zutshi, A., \& Ahmad, N. (2011). An integrated management systems approach to corporate sustainability. European Business Review, 23(4), 353-367. http://dx.doi.org/10.1108/09555341111145744.

Berman, S. J., Christner, R., \& Bell, R. (2010). Actions to implement three potent post-crisis strategies. Strategy and Leadership, 38(5), 26-32. http://dx.doi.org/10.1108/10878571011072057.

Biagio, L. A., \& Batocchio, A. (2005). Plano de negócios - estratégia para micro e pequenas empresas. Barueri: Manole.

Blumentritt, T. (2006). Integrating strategic management and budgeting. The Journal of Business Strategy, 27(6), 73-79. http://dx.doi. org/10.1108/02756660610710382.

Bossidy, L., Charan, R., \& Burck, C. (2002). Execution: the discipline of getting things done. Nova lorque: Crown Business.

Boulesnane, S., \& Bouzidi, L. (2013). The mediating role of information technology in the decision-making context. Journal of Enterprise Information Management, 26(4), 387-399. http://dx.doi.org/10.1108/JEIM-01-2012-0001.

Calandro Junior, J., \& Lane, S. (2007). A new competitive analysis tool: the relative profitability and growth matrix. Strategy and Leadership, 35(2), 30-38. http://dx.doi.org/10.1108/10878570710734516.

Campbell, A. (2017). Comments on 'Corporate strategy and parenting theory', Michael Goold, Andrew Campbell and Marcus Alexander. Long Range Planning, Volume 31, lssue 2, April 1998, Pages 308-314. Long Range Planning, 50(1), 24-27. http://dx.doi.org/10.1016/j. Irp.2016.12.009.

Chatterjee, S., Narayanan, V., \& Malek, W. (2016). How strategy execution maps guided Cisco System's Sales Incentive Compensation plan. Strategy and Leadership, 44(6), 25-34. http://dx.doi.org/10.1108/SL-08-2016-0071.

Cioffi, J. M. (2017). Collaborative care: Using six thinking hats for decision making. International Journal of Nursing Practice, 23(6), 1-7. http://dx.doi.org/10.1111/ijn.12593. PMid:28976053.

Cocks, G. (2010). Emerging concepts for implementing strategy. The TQM Journal, 22(3), 260-266. http://dx.doi.org/10.1108/17542731011035505.

Coulson-Thomas, C. (2013). Implementing strategies and policies. Strategic Direction, 29(3), 33-35. http://dx.doi.org/10.1108/02580541311304643.

Cunha, R. A., \& Borges, M. E. N. (2009). Strategical use of the information generated for the customer support service. Revista de Ciência da Informação, 10(4). Retrieved in 2021, August 20, from http://hdl.handle.net/20.500.11959/brapci/6955

Deif, A. M., \& Elmaraghy, H. (2014). Cost performance dynamics in lean production leveling. Journal of Manufacturing Systems, 33(4), 613-623. http://dx.doi.org/10.1016/j.jmsy.2014.05.010.

Di Vaio, A., Palladino, R., Pezzi, A., \& Kalisz, D. E. (2021). The role of digital innovation in knowledge management systems: A systematic literature review. Journal of Business Research, 123, 220-231. http://dx.doi.org/10.1016/j.jbusres.2020.09.042.

Dubey, R., Gunasekaran, A., Childe, S. J., Bryde, D. J., Giannakis, M., Foropon, C., Roubaud, D., \& Hazen, B. T. (2019). Big data analytics and artificial intelligence pathway to operational performance under the effects of entrepreneurial orientation and environmental dynamism: a study of manufacturing organisations. International Journal of Production Economics, 107599. http://dx.doi. org/10.1016/j.jpe.2019.107599.

Ferreira, S. A., Vieira Neto, J. V., \& Batista, H. M. C. S. (2019). Critical success factors on project and process management in competitive strategy implementation. Brazilian Journal of Operations \& Production Management, 16(4), 605-616. http://dx.doi.org/10.14488/ BJOPM.2019.v16.n4.a6.

Floyd, S. W., \& Wooldridge, B. (1990). Bridging the gap between strategy and operations: the implications of middle management involvement in strategy title. In Proceedings of the 10th International Annual Conference of the Strategic Management Society Conference, Stockholm, Sweden.

Getz, G., \& Lee, J. (2011). Why your strategy isn’t working. Business Strategy Series, 12(6), 303-307. http://dx.doi.org/10.1108/17515631111185932.

Ghalehkhondabi, 1., Ahmadi, E., \& Maihami, R. (2020). An overview of big data analytics application in supply chain management published in 2010-2019. Production, 30, e20190140. http://dx.doi.org/10.1590/0103-6513.20190140.

Goecks, L. S., Santos, A. A., \& Korzenowski, A. L. (2020). Decision-making trends in quality management: a literature review about Industry 4.0. Production, 30, e20190086. http://dx.doi.org/10.1590/0103-6513.20190086.

Hamann, P. M., \& Schiemann, F. (2021). Organizational performance as a set of four dimensions: an empirical analysis. Journal of Business Research, 127, 45-65. http://dx.doi.org/10.1016/j.jbusres.2021.01.012.

Henike, T., Kamprath, M., \& Hölzle, K. (2019). Effecting, but effective? How business model visualisations unfold cognitive impacts. Long Range Planning, 53(4), 101925. https://doi.org/10.1016/j.lrp.2019.101925.

Hu, Y.-P., Chang, 1.-C., \& Hsu, W.-Y. (2017). Mediating effects of business process for international trade industry on the relationship between information capital and company performance. International Journal of Information Management, 37(5), 473-483. http:// dx.doi.org/10.1016/j.jinfomgt.2017.04.004.

Huikku, J., Hyvönen, T., \& Järvinen, J. (2017). The role of a predictive analytics project initiator in the integration of financial and operational forecasts. Baltic Journal of Management, 12(4), 427-446. http://dx.doi.org/10.1108/BJM-05-2017-0164.

lvert, L. K., Dukovska-Popovska, l., Fredriksson, A., Dreyer, H. C., \& Kaipia, R. (2015). Contingency between S\&OP design and planning environment. International Journal of Physical Distribution \& Logistics Management, 45(8), 747-773. http://dx.doi.org/10.1108/ IJPDLM-04-2014-0088.

Kaplan, R. S., \& Norton, D. P. (2000). Organização orientada para a estratégia: como as empresas que adotam o BALANCED SCORECARD prosperam no novo ambiente de negócios. USA: Elsevier.

Kennerley, M., \& Mason, S. (2008). The use of information in decision making, literature review for the audit commission. Reino Unido: Cranfield School of Management.

Kim, C. H., \& Choi, Y. B. (2017). How meritocracy is defined today?: Contemporary aspects of meritocracy. Economia e Sociologia, 10(1), 112-121. http://dx.doi.org/10.14254/2071-789X.2017/10-1/8.

Llonch, M., Bernardo, M., \& Presas, P. (2018). A case study of a simultaneous integration in an SME. International Journal of Quality \& Reliability Management, 35(2), 319-334. http://dx.doi.org/10.1108/IJQRM-11-2016-0193. 
Mcchesney, C., Covey, S., \& Huling, J. (2013). As quatro disciplinas da execução: garanta o foco nas metas crucialmente importantes. USA: Elsevier.

Meneghelli, L. (2016). O ambiente das organizações na era da globalização. Criciúma, SC: ICPG Instituto Catarinense de Pós-Graduação.

Muraliraj, J., Zailani, S., Kuppusamy, S., \& Santha, C. (2018). Annotated methodological review of Lean Six Sigma. International Journal of Lean Six Sigma, 9(1), 2-49. http://dx.doi.org/10.1108/1JLSS-04-2017-0028.

Nejatian, M., Zarei, M. H., Nejati, M., \& Zanjirchi, S. M. (2018). A hybrid approach to achieve organizational agility. Benchmarking, 25(1), 201-234. http://dx.doi.org/10.1108/BlJ-09-2016-0147.

Nielsen, C., Lund, M., \& Thomsen, P. (2017). Killing the balanced scorecard to improve internal disclosure. Journal of Intellectual Capital, 18(1), 45-62. http://dx.doi.org/10.1108/JlC-02-2016-0027.

Nunhes, T. V., Motta Barbosa, L. C. F., \& de Oliveira, O. J. (2017). Identification and analysis of the elements and functions integrable in integrated management systems. Journal of Cleaner Production, 142, 3225-3235. http://dx.doi.org/10.1016/j.jclepro.2016.10.147.

Osterwalder, A., \& Pigneur, Y. (2010). Business model generation: a handbook for visionaries, game changers, and challengers. Hoboken: John Wiley \& Sons.

Project Management Institute, Inc. - PMI. (2017). A guide to the project management body of knowledge (PMBOK guide) (6th ed.). Filadélfia: Project Management Institute, Inc.

Prybutok, G. L. (2018). Ninety to Nothing: a PDSA quality improvement project. International Journal of Health Care Quality Assurance, 31(4), 361-372. http://dx.doi.org/10.1108/IJHCQA-06-2017-0093. PMid:29790446.

Raps, A. (2005). Strategy implementation - an insurmountable obstacle? Handbook of Business Strategy, 6(1), 141-146. https://doi. org/10.1108/08944310510557152.

Sampaio, P., Saraiva, P., \& Domingues, P. (2012). Management systems: integration or addition? International Journal of Quality \& Reliability Management, 29(4), 402-424. http://dx.doi.org/10.1108/02656711211224857.

Shamah, R. A. M. (2013). A model for applying lean thinking to value creation. International Journal of Lean Six Sigma, 4(2), $204-224$. http://dx.doi.org/10.1108/20401461311319365.

Shen, L., Zhou, J., Skitmore, M., \& Xia, B. (2015). Application of a hybrid Entropy-McKinsey Matrix method in evaluating sustainable urbanization: a China case study. Cities, 42(Pt B), 186-194. https://doi.org/10.1016/j.cities.2014.06.006.

Speculand, R. (2009). Six necessary mind shifts for implementing strategy. Business Strategy Series, 10(3), 167-172. http://dx.doi. org/10.1108/17515630910956589.

Srivastava, A. K. (2013). Modeling strategic performance factors for effective strategy execution. International Journal of Productivity and Performance Management, 62(6), 554-582. http://dx.doi.org/10.1108/IJPPM-11-2012-0121.

Srivastava, A. K., \& Sushil, (2015). Modeling organizational and information systems for effective strategy execution. Journal of Enterprise Information Management, 28(4), 556-578. http://dx.doi.org/10.1108/JEIM-09-2013-0071.

Srivastava, A. K., \& Sushil, (2017). Alignment: the foundation of effective strategy execution. International Journal of Productivity and Performance Management, 66(8), 1043-1063. http://dx.doi.org/10.1108/1JPPM-11-2015-0172.

Stiles, P., \& Taylor, B. (2002). Boards at work: how directors view their roles and responsibilities. Oxford: Oxford University Press. http:// dx.doi.org/10.1093/acprof:oso/9780199258161.001.0001

Tortorella, G., Viana, S., \& Fettermann, D. (2015). Learning cycles and focus groups: a complementary approach to the A3 thinking methodology. The Learning Organization, 22(4), 229-240. http://dx.doi.org/10.1108/TL0-02-2015-0008.

Voola, R., \& O'Cass, A. (2010). Implementing competitive strategies: the role of responsive and proactive market orientations. European Journal of Marketing, 44(1-2), 245-266. http://dx.doi.org/10.1108/03090561011008691.

Vuorinen, T., Hakala, H., Kohtamäki, M., \& Uusitalo, K. (2018). Mapping the landscape of strategy tools: a review on strategy tools published in leading journals within the past 25 years. Long Range Planning, 51(4), 586-605. http://dx.doi.org/10.1016/j.lrp.2017.06.005.

Zhang, M., Gao, Q., Wheeler, J. V., \& Kwon, J. (2016). Institutional effect on born global firms in China: the role of Sun Tzu's The Art of War strategies. Journal of Asia Business Studies, 10(1), 1-19. http://dx.doi.org/10.1108/JABS-11-2014-0084. 